\title{
"Investigation of Rotating Instability in the Last Stage of Low Pressure Turbine during Low volume flow Operation"
}

\author{
Dilip Kumar Garg ${ }^{1}$, Shrinivas Chambalwar ${ }^{2}$, Jayant Sarode ${ }^{3}$, Ajay Dhanopia ${ }^{4}$ \\ ${ }^{1}$ Department of Mechanical Engineering, Vit University, Vellore, Tamil Nadu \\ ${ }^{4}$ Swami Keshwanand Institute of Engineering and Technology, Jaipur, Rajasthan
}

\begin{abstract}
The rotating instability flow phenomenon is numerically studied earlier in the laststage of low pressure model steam turbine operated at very low mass flow rate. This kind of instability imposes a major risk to the mechanical integrity of last stage moving blades (LSMBs) in low-pressure (LP) steam turbines.Aim is to predict correctly the unsteady flow phenomena and their effects. A Numerical analysis using a validated unsteady non-linear time-domain CFD solver is performed. A computational study on two different selfdesigned $3 D$ blade sections is subsequently carried out. These results show that a rotating instability in a turbine blade configuration can be captured by $3 D$ model also.In comparison to the many previous investigations, the results suggest that the beginning and the development of rotating instabilities can also occur without $3 D$ and tip leakage flows, although the very accuracy is possible only when comparing the experimental results with $3 D$ solutions.
\end{abstract}

\section{Keywords}

Last Stage Moving Blades, Low Volume Flow, Blade Passing Frequency, Reynolds Averaging Navier-Stoke

\section{Introduction}

To cope up with the power generation needs and satisfying environmental requirements, combined cycle power plants have been widely developed. The system should be reliable and flexible but it would bring risk to steam turbine designs. The critical components of steam turbine in terms of flexible operation are those sustaining higher temperature and higher pressure such as the inlet valves or the rotor which can suffer from low cycle fatigue under high thermal transients. Other vulnerable parts are the Last Stage Moving Blades (LSMBs) of the low-pressure turbines. The operating regime of the LSMB is characterized by the volume flow leaving the stage. The volumeflow can vary due to a reduction in inlet mass flow to the stage under low load conditions of the power plant, or with large extraction mass flows for district heating, or steam used for chemical processes. Also a poor condenser pressure also leads to a reduced volume flow as the fluid density is rising while maintaining the mass flow.

Figure. 1 shows the general characteristic of a turbine stage if the volume flow is varied. With a reduction in volume flow the work output is reduced and consequently the power output. A further reduction in volume flow leads to a power consumption of the stage, where energy is returned from the shaft to the fluid. This region is sometimes called ventilation region because the rotor blade is swirling in the globally slow moving fluid with small pressure differences. Here the term Low Volume Flow (LVF) operation is used[1].

DOI : 10.14810/ijmech.2015.4204 


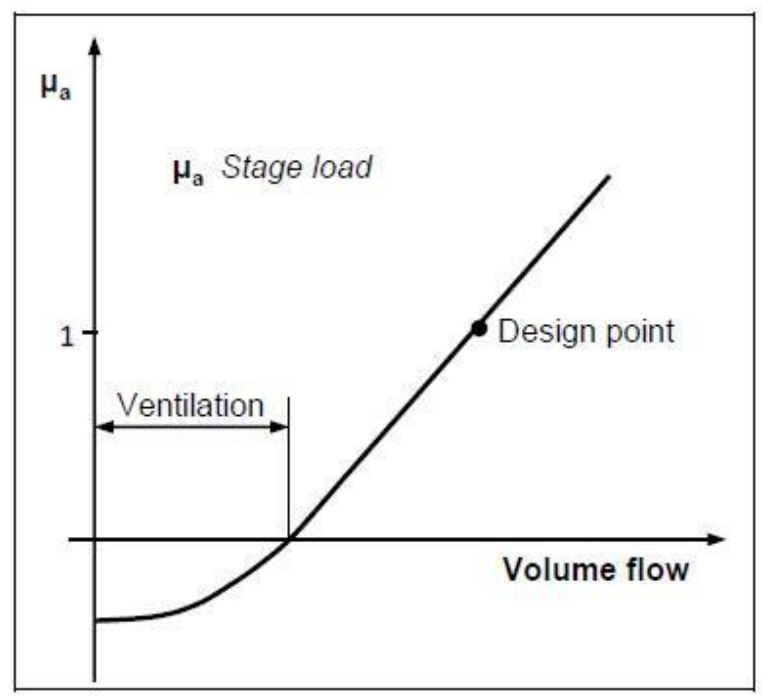

Fig. 1 General characteristic of low pressure turbine under variable flow

Such off design conditions may cause aero elastic problems mainly to the LSMBs and also putting them at a risk of damage due to windage i.e. strongly separated flow. It has been observed that since a steam turbine may undergo variable part load operation for a considerable part of time, high dynamic stresses that are associated with the blade excitation must be avoided or at least controlled to be at below at certain level. Therefore it is necessary to investigate the flow behavior of LSMBs and corresponding aero elastic phenomena's under low volume flow operations. This would directly help the designers in prediction of any mechanical failure and to reduce the risk. Thus this would play a major role in extending the working range and improving the flexibility of steam turbines [2].In past there were many different methods has been used to understand the unsteady aerodynamic flow phenomenon described. A computational study has beenperformed for measuring unsteady pressure measurements.

\section{Literature Review}

The fundamental investigation into the flow field under LVF conditions is historically related to the development of district heating and extraction from steam turbines. This development was mainly driven by the wide-spread use of district heating in the former Soviet Union and (primarily East) Germany in 1970's. However, a number of LSMB failures occurred in order to maximize the heat extraction, the mass flow through the LP turbine section is practically cut off, leading to an unacceptable heating-up of the turbine blades and also combined with high dynamic stresses in the turbine blades. Due to the highly complex nature of the flow field under ventilation most of the research in the past has been performed using either model turbines or measurement in power plants [1]. 


\section{Time Averaged Flow Field}

Troyanovskii describes how the flow structure changes with reduction in the volume flow. The span wise variation of reaction is $15 \%$ at the hub and $65 \%$ at the tip in the last stage of steam turbine at design conditions. Since the hub is a low reaction section so it is first to be affected by low volume flow. As the steam can no longer pass through the zone close to the root, it is redirected towards the tip and hence, a separation region develops behind the rotor blade. In his experiment Lagunetal also analyzed that under ventilation parts of the rotor blade operate as a compressor. As well as the hub separation zone behind the rotor blade, another separation zone establishes itself at even lower volumetric flows close to the casing in the axial gap between stator and rotor blade. This torus vortex moves in a circumferential direction with a considerable velocity, which is close to the rotational velocity of the rotor blade. The two separation zones and the centrifugal force guide the flow through the rotor blade into a diagonal direction with a major radial velocity component, as shown in Figure 2. The highest temperatures are measured at the blade tips at the inlet of the last blade row.

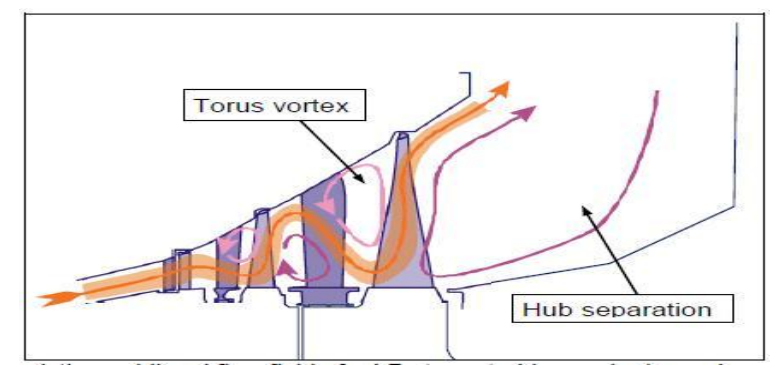

Fig. 2 Flow Field of A Low Pressure Turbine Under Low Volume Flow Operation [1].

stresses get increased sharply with 2-3 times higher than the dynamic stresses at rated conditions while operated at LVF. This increase of stress is due to the change of turbine operational mode to compressor type mode where there is drastic increase of pressure and velocity of flow in tip region of LSMB. Engelke et al. [5] showed the variation of stress in a model steam turbine close to the point where the last stage produces zero power refer fig 3 .

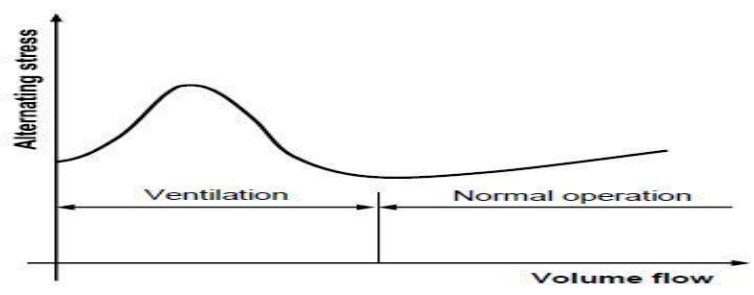

Fig. 3 Variation of Stresses with the Volume Flow. 


\section{Blade excitation}

In past various experiments were conducted in order to find out the exact reasons for the excitation of blades. The resonance from non-synchronous excitation is more difficult to predict and avoid also. Such excitation can be present over a wide frequency range. Furthermore a new concept of excitation called flutter or stall flutter also came into the existence. Flutter is an aeroelastic instability that leads to the failure of blades. Due to a small vibration of blade surrounding flow field gets changed in such a way that vibration gets amplified by the unsteady fluid forces. From research it has been found out that flutter occurs during low volume flow if we raise the condenser pressure. Shnee et al. [6] observed theApart from various reasons of the excitation some of them also are the angle of attack caused a separation that will lead to excitation, separation zone at the hub, tip leakage flow etc.

\section{Unsteady Flow Field}

In the University of Stuttgart an experimental study on a model turbine was conducted at very low mass flow conditions [4]. Unsteady Pressure probes are used to detect the pressure fluctuations in the region of LSMBs. In the analysis a relation between high amplitude disturbances and the blade excitation was determined. The sharp pressure peaks were found at certain frequencies other than the Blade Passing Frequency (BPF). These peaks were evenly spaced as shown in fig 4.Thus the rotating instability in LSMBs can stay is a sustainable manner at a globally stable condition. Thus it is important to have proper prediction whether or not a rotating instability would occür or not:

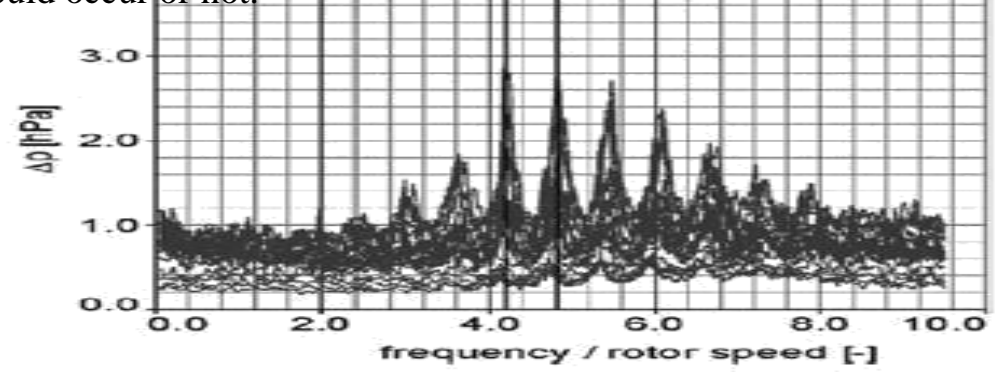

Fig. 4 Frequency spectra of total pressure in axial gap of a last stage of a model turbine [4]

\section{Numerical Methods}

It would be a tedious task for doing numerical investigation of the flow field under ventilation. Various experimental measurements are needed to estimate the onset of separation of flow. But the analysis is limited only to a minimum mass flow of $20 \%$ i.e $1.15 \mathrm{Kg} / \mathrm{s}$. It is known that the mostly used coordinate system for use in turbo machinery rotors is the relative or rotating coordinate system. The frame of reference is attached to the rotor So it rotates with an angular velocity $\omega$ about the main axis. The basic reason behind using moving reference of frame is if the flow field is transient when viewed in a stationary frame can become steady when viewed in a 
this frame. In Rotating Frame of Reference the Continuity Equation is shown as:

$\overrightarrow{\mathrm{V}}=\overrightarrow{\mathrm{W}}+\overrightarrow{\omega \mathrm{X} \mathrm{r}}$

As the absolute Velocity Vector is

Where $\quad \mathrm{W}=$ Relative Velocity Vector

$\omega=$ Angular Velocity

$\mathrm{r}=$ Position Vector

$\underline{\partial \rho}+(\mathrm{V}=\mathrm{W}+\omega \mathrm{X} \mathrm{r}) \cdot \nabla \rho+\rho \nabla \cdot(\omega \mathrm{X} \mathrm{r})=0$

$\partial \mathrm{t}$

Where $\underline{\partial}$ and $(\omega \mathrm{X} \mathrm{r})$ are the local rate of change respectively with respect to a stationary

$\partial \mathrm{t}$

observer.

In the low Pressure stage of steam turbines under LVF, turbulent flow is also expected to be present both in the boundary layers as well as in the free stream turbulence. In order to be close to the Navier-Stokes Equations along with turbulence is Reynolds Averaging Navier-Stokes Equations (RANS). Here k- $\varepsilon 2$ equations turbulence model is used with the energy equation is also applied as it leads to higher numerical stability without sacrificing the accuracy.

\section{Blade Design and Analysis}

Due to unavailability of the blade original parameters we design a new blade section considering suitable parameters. The blade is designed in the solid works 2013. Fig 5 will shows the 2D sketch design of blade. The blade parameters taken by us are shown as below:

$\operatorname{Pitch}(\mathrm{s})=24.94 \mathrm{~mm}$

Chord length $(\mathrm{c})=28.84 \mathrm{~mm}$

Stagger angle $=30^{\circ}$

Inner radius of curvature $=47.05 \mathrm{~mm}$

Outer radius of curvature $=39.9 \mathrm{~mm}$

Axial chord $=24.4 \mathrm{~mm}$

Throat diameter $=17.60 \mathrm{~mm}$ 


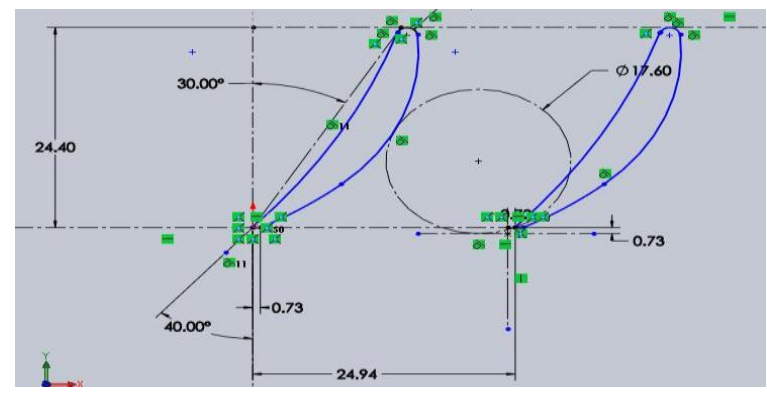

Fig. 5 Blade geometry of rotor with parameters

The blade is then exported to the ANSYS WORKBENCH FLUENT for 3 D CFD Analysis. Since from previous work, it is observed that the model air behaves in a similar manner as of the actual steam turbine. So in the current study we are going to analyze the flow of air with the parameters shown in the table 1 for different mass flow rate at constant rpm and determine the changes occurred.

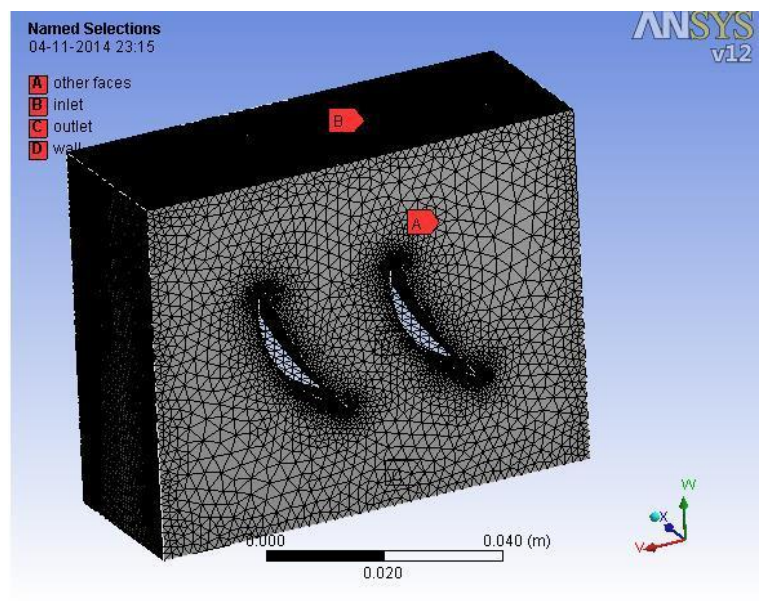

Fig. 6 Meshing of the blade geometry in a rectangular box

In the Workbench the geometry get enclosed in the rectangular box selection Fig.6. The computational mesh for this rectangular geometry is mapped face mesh with 50 no. of total divisions of element size which results in a course meshing. The inlet flow angle is $20^{\circ}$. We are doing 100 iterations of residuals in order to converge the solution to get more accuracy. 
International Journal of Recent advances in Mechanical Engineering (IJMECH) Vol.4, No.2, May 2015

Table 1 Design Data for air model turbine

\begin{tabular}{ll} 
Working parameters & \multicolumn{1}{c}{ Values } \\
Design Rotor Speed & $6300 \mathrm{rpm}$ \\
Design Mass Flow & $5.75 \mathrm{Kg} / \mathrm{s}$ \\
Total inlet Pressure & $3.3 \mathrm{bar}$ \\
Total inlet Temperature & $430 \mathrm{~K}$ \\
Total Exit Pressure & $1.01 \mathrm{bar}$ \\
Average Flow coefficient & 0.79 \\
\hline
\end{tabular}

\section{Results and Discussion:}

As we are comparing the experimental results with the computational results on model air turbine by keeping the same rotational speed of rotor as $6300 \mathrm{rpm}$ and reducing the mass flow rate from $5.75 \mathrm{Kg} / \mathrm{s}$ to $1.15 \mathrm{Kg} / \mathrm{s}$ and analyze the changes that will be going to take place across the suction and pressure sides of the blade geometry. Fig7. shows the pressure distributions across the blade surface compared with the experimental data. The comparison is some what similar to the experimental results. The plot of static pressures across the surface of the blade is shown in the fig8. The static pressure plot on the surface at design mass flow rate fig (a) and reduced mass flow rate fig (b). Clearly indicates how the pressure rises due to reduce in the mass flow rate at the last stage of low pressure turbines

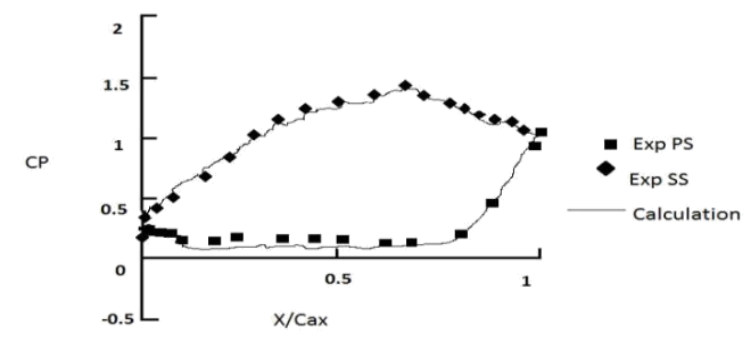

Fig. 7 Steady pressure distribution compared to the experimental data. 
International Journal of Recent advances in Mechanical Engineering (IJMECH) Vol.4, No.2, May 2015

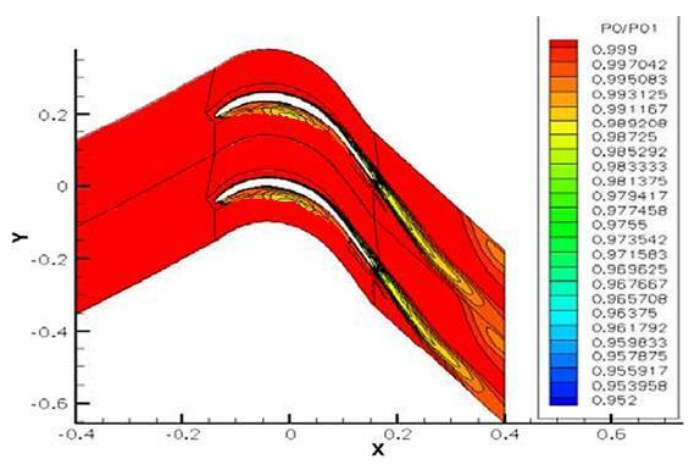

Fig.(a)

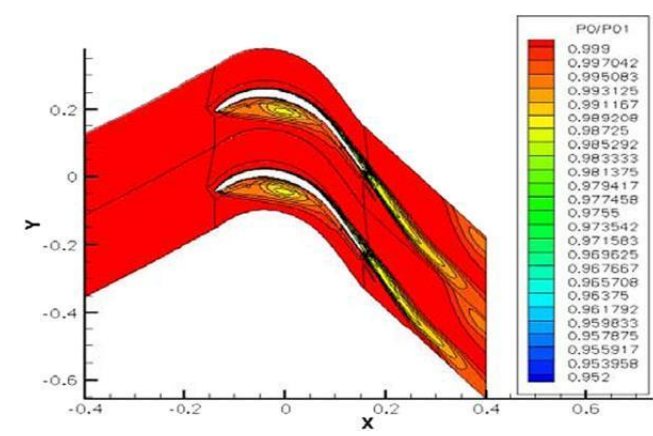

Fig.(b)

Fig. 8 Shows the plot of static pressure at design and off design mass flow conditions

The main reason behind the pressure rise is that as the mass flow rate is reduced in the LSMBs at constant speed, the flow entering the blades of stator vanes and rotor experiences suction side incidence. For showing this refer fig 9, which shows the 2D analysis in which the flow leaves the trailing edge without deviation, i.e., in the direction along the blade camber's tangent at the trailing edge: As the volume flow gets reduced, it results in the reduction of the axial velocity component. As the rotor speed is constant, the circumferential velocity of the rotor also remains constant, as is the casein power generation process due to the constant grid frequency imposed upon the generator. This results in the reduction of the magnitude of the relative velocity that

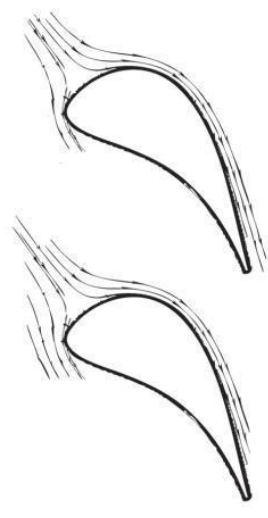

Stator vanes

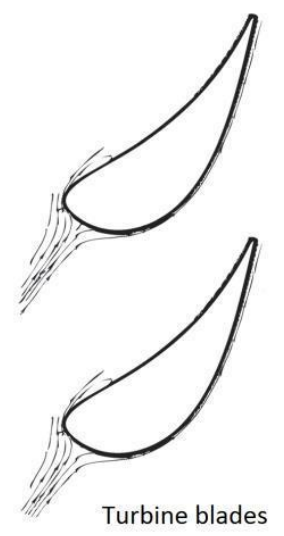

Fig. 9 Shows the 2D analysis of flow over the stator and rotor blades

causes the possible swirl against the rotation of the rotor due to which suction side pressure increases abnormally. Once the critical mass flow is reached, the suction side incidence causes the development of separation bubble on the pressure side of the blades. On further decreasing the mass flow rate the bubble further expands in axial and circumferential direction that is responsible for increase of pressure. 
International Journal of Recent advances in Mechanical Engineering (IJMECH) Vol.4, No.2, May 2015

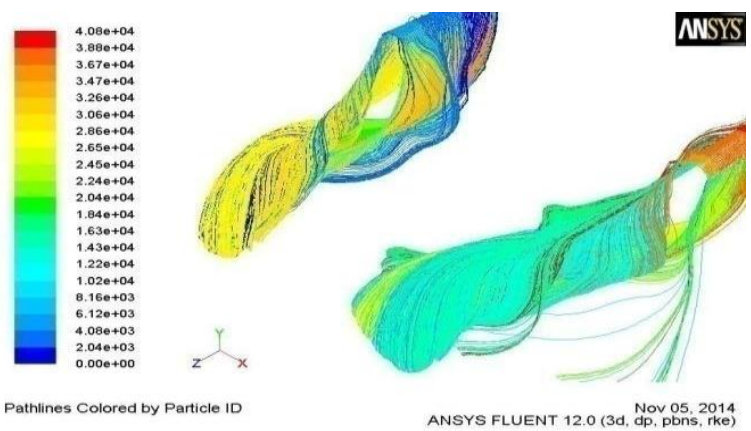

Fig. 10 Complex flow pattern over the blade at $20 \%$ of design Mass flow rate.

\section{Conclusion:}

The numerical investigation of the rotating instability of the LSMBs of Low Pressure model air turbine has been done successfully. The results are also compared with the experimental results. However certain differences still exist due to self defined blade geometry. Finally in the analysis part we also got the simulated flow result of the air in LSMBS at very low mass flow rate of about $1.15 \mathrm{Kg} / \mathrm{s}(20 \%$ of the design flow rate). It is clearly seen that the flow gets very complex shape due to turbulence effects involved here so it become very difficult to do the research on the rotating instability. However it we use exact geometry parameters we would get very close to the actual results that will be very helpful to understand the exact cause of instability.

\section{References:}

[1]. Megerle, Benjamin. "Unsteady aerodynamics of low-pressure steam turbinesoperatingunderlowvolumeflowconditions."PhDdiss.,ÉCOLEPOLYTECHNIQUE FÉDÉRALE DE LAUSANNE,2014.

[2] L.Y. Zhang, H.Stiier, L.He,January 2013 "A Numerical Investigation of Rotating Instability in Steam Turbine Last Stage,” ASME J. Turbomach.,Vol.135 / 011009-1

[3] Matthias Binner, Joerg R. Seume, "Flow Patterns in High Pressure Steam Turbines During LowLoad Operation"

[4] Gerschu" tz, W., Casey, M., and Truckenmu"ller, F., 2005, "Experimental Investigations of Rotating Flow Instabilities in the Last Stage of a Low-Pressure Model Steam Turbine during Windage," Proc. IMechE, Part A: J. Power Energy, 219, pp. 499-510

[5] W. Engelke, M. Gloger, W. Maly, and H. Termuehlen, "Large steam turbine freestanding blade development based on 30 years of experience", in AMERICAN POWER CONFERENCE, Chicago, Illinois, 1978.

[6]. Y. Shnee, O. Ponomarev, V. Slabchenko, M. Zatsev, and M. Fedorov, "Influence of the operational factors on dynamic stresses in moving blades of a turbine stage", Teploenergetika, vol. 21, pp. 49-52, 1974

\section{Acknowledgement:}

A special thanks is given to our guide Dr. G Venkatachalam for supporting our work and helped us at various phases of research work. 